\title{
Creep of magnesium strengthened with high volume fractions of yttria dispersoids
}

\author{
B.Q. Han ${ }^{1}$, D.C. Dunand * \\ Department of Materials Science and Engineering, Northwestern University, 2225 North Campus Drive, Evanston, IL 60208, USA
}

Received 27 July 2000

\begin{abstract}
Creep experiments were performed on dispersion-strengthened-cast magnesium (DSC-Mg), consisting of unalloyed magnesium with $1 \mu \mathrm{m}$ grain size containing $30 \mathrm{vol} \%$ of $0.33 \mu \mathrm{m}$ yttria particles. Strain rates were measured for temperatures between 573 and $723 \mathrm{~K}$ at compressive stresses between 7 and $125 \mathrm{MPa}$. DSC-Mg exhibits outstanding creep strength as compared with other magnesium materials, but is less creep resistant than comparable DSC-Al and other dispersion-strengthened aluminum materials. Two separate creep regimes were observed in DSC-Mg, at low stresses $(\sigma<30 \mathrm{MPa})$, both the apparent stress exponent $\left(n_{\text {app }} \approx 2\right)$ and the apparent activation energy $\left(Q_{\mathrm{app}} \approx 48 \mathrm{~kJ} \mathrm{~mol}^{-1}\right)$ are low, while at high stresses $(\sigma>34 \mathrm{MPa})$, these parameters are much higher $\left(n_{\text {app }}=9-15\right.$ and $\left.Q_{\text {app }}=230-325 \mathrm{~kJ} \mathrm{~mol}^{-1}\right)$ and increase, respectively, with increasing temperature and stress. The low-stress regime can be explained by an existing model of grain-boundary sliding inhibited by dispersoids at grain-boundaries. The unexpectedly low activation energy (about half the activation energy of grain boundary diffusion in pure magnesium) is interpreted as interfacial diffusion at the $\mathrm{Mg} / \mathrm{Y}_{2} \mathrm{O}_{3}$ interface. The high-stress regime can be described by dislocation creep with dispersion-strengthening from the interaction of the submicron particles with matrix dislocations. The origin of the threshold stress is discussed in the light of existing dislocation climb, detachment and pile-up models. (C) 2001 Elsevier Science B.V. All rights reserved.
\end{abstract}

Keywords: Magnesium; Yttria; Creep; Oxide-dispersion-strengthened materials; Metal matrix composites; Threshold stress

\section{Introduction}

Oxide-dispersion-strengthened aluminum (ODS-Al) alloys produced by powder-metallurgy techniques exhibit outstanding elevated-temperature performance and creep resistance, much higher than precipitationstrengthened alloys or discontinuously-reinforced aluminum metal matrix composites (Al-MMC). The excellent creep resistance of ODS-Al results from finelydispersed, incoherent, unshearable, submicron particles with low volume fractions (typically below 10 vol.\%). These particles strongly impede the movement of dislocations, an effect which can be modeled by a threshold stress below which dislocation creep is immeasurably

\footnotetext{
* Corresponding author. Tel.: +1-847-4915370; fax: +1-8474676573.

E-mail address: dunand@northwestern.edu (D.C. Dunand).

${ }^{1}$ Present address: Department of Metallurgical Engineering, McGill University, Montreal, Canada PQ H3A 2B2.
}

slow or nil [1,2]. Recently, melt pressure infiltration has been used to fabricate dispersion-strengthened-cast aluminum (DSC-Al) containing very high volume fractions (20-40 vol.\%) of relatively coarse alumina dispersoids $(0.3-0.6 \mu \mathrm{m})$ [3]. DSC-Al exhibits a large threshold stress as compared with other ODS aluminum materials due to the high volume fraction of particles interacting with dislocations $[4,5]$.

Magnesium alloys are attractive for applications at elevated temperatures in the automobile and aircraft engine industries, because they have the lowest density of all technologically-relevant alloys. While oxide dispersoids have been used in aluminum and many other metallic systems for high-temperature strengthening, only a few, relatively old investigations on ODS-Mg materials exist [6-8], this is due in large part to the difficulty of using powder metallurgy for magnesium. A solution to this processing problem is to apply to magnesium the high-temperature melt infiltration technique used to fabricate creep-resistant DSC-Al. We 
recently described in a previous publication [9] such a DSC-Mg material containing 30 vol. $\%$ of submicron yttria dispersoids, which was found to exhibit very high compressive strength and stiffness at room-temperature.

In the present paper, we report experimental compressive creep results for the above DSC-Mg material [9]. Its creep deformation mechanisms are analyzed in the light of existing models based on particle-dislocation interactions, and its creep properties are compared with those of existing high-temperature aluminum- and magnesium-base materials.

\section{Materials and experimental procedure}

The material used in this study was DSC-Mg consisting of $99.9 \%$ pure magnesium with about 30 vol. $\%$ of submicron yttria $\left(\mathrm{Y}_{2} \mathrm{O}_{3}\right)$ dispersoids. The material was fabricated by Chesapeake Composites Corp. (Newcastle, DE) by the same melt infiltration technique described in [3] for DSC-Al (which is composed of unalloyed aluminum and $25-30$ vol. $\%$ of $0.28 \mu \mathrm{m}$ alumina dispersoids). For DSC-Mg, yttria was chosen as dispersoid because of its thermodynamical stability with molten magnesium and its availability in chemicallypure form as submicron powder. The average diameter of the yttria particles is about $0.33 \mu \mathrm{m}$ as observed by electron microscopy, and their volume fraction is 29.7 vol.\%, as determined by density measurements [9]. The as-cast DSC-Mg billets with $42.9 \mathrm{~mm}$ diameter were extruded at $673 \mathrm{~K}$ into rods with $9.5 \mathrm{~mm}$ diameter.

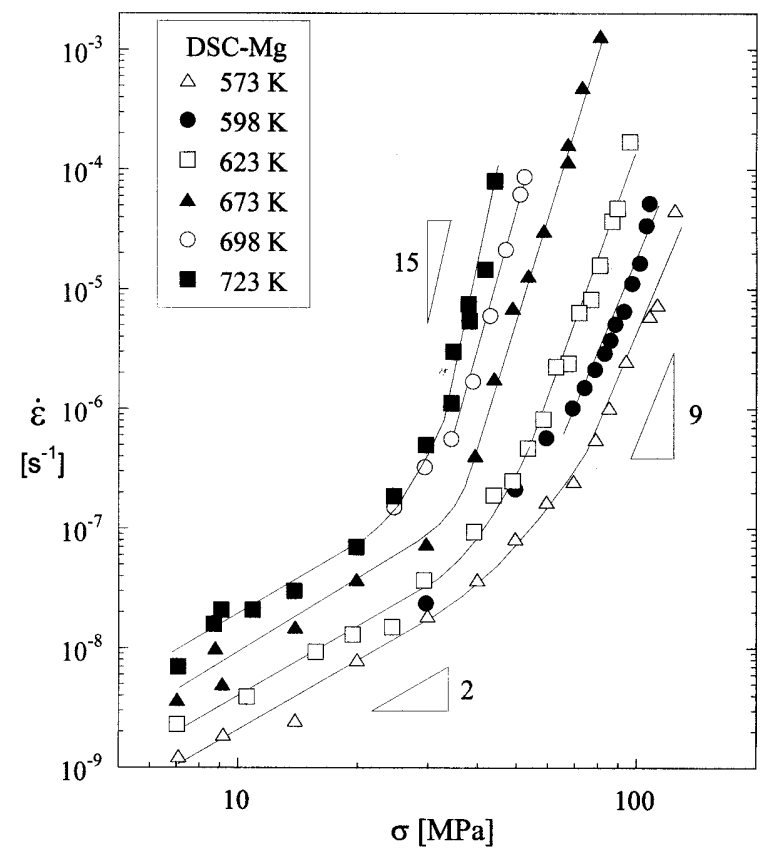

Fig. 1. Strain rate as a function of true stress for DSC-Mg at temperatures from 573 to $723 \mathrm{~K}$.
Cylindrical specimens with $6.35 \mathrm{~mm}$ diameter and $12.70 \mathrm{~mm}$ height were machined along the extrusion direction. Constant-load compression tests were performed in air at engineering stresses from 7 to $125 \mathrm{MPa}$ and at temperatures from 573 to $723 \mathrm{~K}\left(T / T_{\mathrm{m}}=0.62-\right.$ 0.79). The upper test temperature was dictated by the maximum temperature at which the thin protective oxidation film of magnesium formed in air still grows slowly [10]. Compression testing was chosen over tensile testing, because cavitation has been found to be the rate-controlling deformation mechanism during tensile creep of DSC-Al [4,11]. The tests were run using a compression-fixture in a tensile creep frame using a three-zone furnace with a temperature constant within $1 \mathrm{~K}$. To reduce friction at the specimen/platen interface, a high-temperature lubricant was sprayed on both ends of specimens. After heating to the test temperature in about $15 \mathrm{~min}$ and soaking at the test temperature for 1 $\mathrm{h}$, the specimen was mechanically loaded in about $3-4$ s. The displacement of the platens of the compressionfixture was measured by an extensometer connected to a linear voltage displacement transducer with a resolution of $0.5 \mu \mathrm{m}$, and recorded by a computerized data acquisition system. Each specimen was subjected to a series of increasing stress levels, for which the minimum strain rate was measured. Specimen were found to deform uniformly up to compressive strains of about $15 \%$. At higher strains, specimen bulging was observed and the corresponding creep data was not used because of the non-uniaxial state of stress.

The microstructure of the crept specimens was examined using a Hitachi H700 transmission electron microscope (TEM) operating at $200 \mathrm{kV}$. TEM samples were cut with a diamond saw along the extruded direction and manually ground to a thickness of about $50 \mu \mathrm{m}$. Disks with a diameter of $3 \mathrm{~mm}$ were punched, polished and dimpled to a thickness of about $20 \mu \mathrm{m}$. Thinning to perforation was finally performed on a Precision Ion Polishing System (Gatan Model 691) with a voltage of about $4 \mathrm{keV}$, a current of $20 \mu \mathrm{A}$, and a gun angle of $6^{\circ}$.

\section{Experimental results}

Fig. 1 shows the minimum strain rate $\dot{\varepsilon}$ as a function of the true stress $\sigma$ (calculated at the strain where the minimum strain rate was achieved), plotted in a double logarithmic manner according to the general power-law constitutive creep equation:

$\dot{\varepsilon}=K \sigma^{n_{\text {app }}} \exp \left(-\frac{Q_{\text {app }}}{R T}\right)$

where $K$ is the creep constant, $n_{\text {app }}$ the apparent stress exponent, $Q_{\text {app }}$ the apparent activation energy, $T$ the absolute temperature and $R$ the gas constant. Fig. 1 shows that two distinct stress regimes exist above and 
Table 1

Apparent stress exponent of extruded DSC-Mg

\begin{tabular}{llllllc}
\hline & $573 \mathrm{~K}$ & $598 \mathrm{~K}$ & $623 \mathrm{~K}$ & $673 \mathrm{~K}$ & $698 \mathrm{~K}$ & $723 \mathrm{~K}$ \\
\hline$\sigma<30 \mathrm{MPa}$ & 1.9 & - & 1.8 & 2.1 & - & 2.0 \\
$\sigma>34 \mathrm{MPa}$ & 8.8 & 9.1 & 9.9 & 10.9 & 13.3 & 15.0 \\
\hline
\end{tabular}

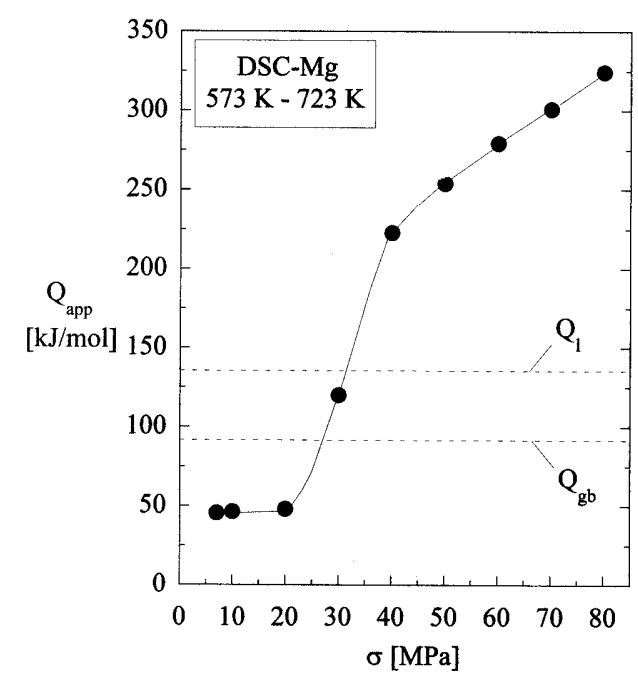

Fig. 2. Apparent activation energy as a function of stress for DSC$\mathrm{Mg}$.

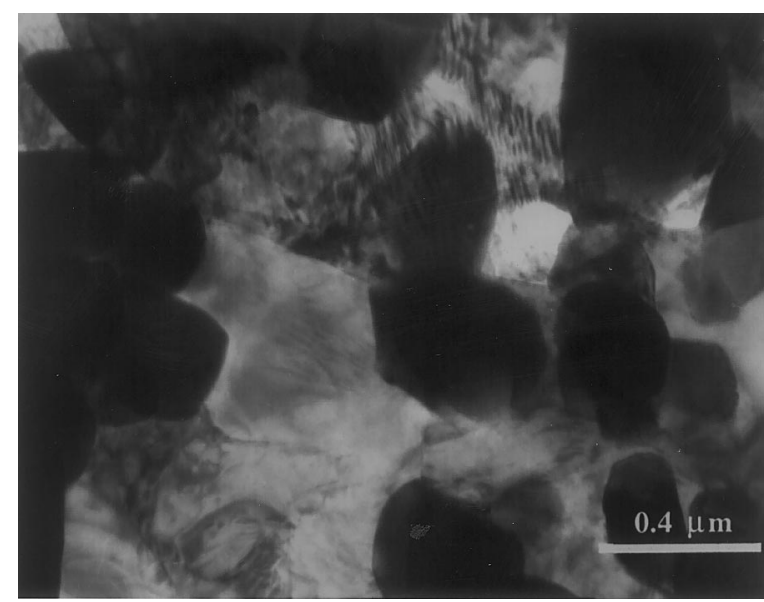

Fig. 3. TEM micrograph of DSC-Mg after creep deformation at 623 $\mathrm{K}$ for $36 \mathrm{~h}$ (extrusion direction parallel to the micrograph plane).

below about $30 \mathrm{MPa}$. The apparent stress exponents from the best-fit lines in these two stress regions are listed in Table 1; they are constant at $n_{\text {app }}=2$ in the low-stress regime $(\sigma<30 \mathrm{MPa})$ but increase with increasing temperatures from $n_{\text {app }}=9$ at $573 \mathrm{~K}$ to $n_{\text {app }}=$ 15 at $723 \mathrm{~K}$ in the high-stress regime $(\sigma>34 \mathrm{MPa})$. These values are higher than the stress exponent values $n=1$ and 5 expected for pure magnesium deforming by diffusional and dislocation creep, respectively [12]. The stress dependence of the apparent activation energy measured between 573 and $723 \mathrm{~K}$ is shown in Fig. 2 .
The apparent activation energy in the low-stress regime $\left(Q_{\text {app }}=48 \mathrm{~kJ} \mathrm{~mol}^{-1}\right)$ is about half the activation energy of grain boundary diffusion in pure magnesium $\left(Q_{\mathrm{gb}}=92 \mathrm{~kJ} \mathrm{~mol}^{-1}[12]\right)$. The apparent activation energy in the high-stress regime increases from 230 to 325 $\mathrm{kJ} \mathrm{mol}{ }^{-1}$ with increasing stress from 40 to $80 \mathrm{MPa}$, and is much larger than the activation energy of lattice diffusion in magnesium $\left(Q_{1}=135 \mathrm{~kJ} \mathrm{~mol}^{-1}\right.$ [12]).

As reported in more detail in our previous publication [9], TEM observations of extruded DSC-Mg prior to creep testing revealed that the great majority of yttria particles are distributed on grain boundaries and that matrix grains are equiaxed in shape, about $0.9 \mu \mathrm{m}$ in size, and separated from each other by high-angle grain boundaries. After creep testing, matrix grains maintained their equiaxed shape and high-angle boundaries, as illustrated in Fig. 3 for a sample crept at $623 \mathrm{~K}$ for $36 \mathrm{~h}$. The matrix grains have a mean linear intercept of $\bar{L}=0.57 \pm 0.28 \mu \mathrm{m}$ for 11 grains, giving an average spatial grain diameter [13] $D=1.75 \bar{L}=1.0 \mu \mathrm{m}$, which is within experimental error the same as in the untested state $(0.9 \mu \mathrm{m})$. As expected from the pinning effect of the dispersoids, grain growth thus did not occur during creep testing of DSC-Mg, as also observed in DSC-Al with $25 \%$ submicron $\mathrm{Al}_{2} \mathrm{O}_{3}$ particles [3].

\section{Discussion}

\subsection{Low-stress regime}

As seen in Fig. 1, the low-stress regime of DSC-Mg is characterized by (i) very low creep rate magnitude, (ii) low stress sensitivity $\left(n_{\text {app }}=2\right)$ and (iii) low temperature sensitivity $\left(Q_{\mathrm{app}}=48 \mathrm{~kJ} \mathrm{~mol}^{-1}\right)$. For pure magnesium with the same grain size and in the same temperature and stress window, diffusional creep controlled by grain-boundary diffusion is predicted to be the dominant deformation mechanism [12]. Using a stress exponent of unity $(n=1)$, an activation energy equal to that for grain-boundary diffusion $\left(Q_{\mathrm{gb}}=92 \mathrm{~kJ} \mathrm{~mol}^{-1}\right)$ and the appropriate creep constant [12], Eq. (1) predicts strain rates for pure magnesium that are eight to nine orders of magnitude higher than observed for DSC-Mg. Thus, the yttria particles affect all three parameters of the creep equation (Eq. (1)) by lowering $K$ and $Q$ and increasing $n$ as compared with pure magnesium. Burton [14] reviewed many diffusional creep studies of dispersion-strengthened alloys and showed empirically that inhibition of diffusional creep is observed for high dispersoid volume fraction and/or high dispersoid melting point (with respect to the matrix). DSC-Mg falls within this regime of high volume fraction and melting point, which also contains the ODS systems $\mathrm{Mg} / \mathrm{MgO}$, $\mathrm{Cu} / \mathrm{Al}_{2} \mathrm{O}_{3}$ and $\mathrm{Au} / \mathrm{Al}_{2} \mathrm{O}_{3}$ [14]. Inhibited diffusional creep in dispersion-strengthened alloys can be described 
mechanistically by a threshold stress for which many models have been proposed, as reviewed by Burton [14]. While a threshold stress can be calculated from the DSC-Mg data to justify the higher apparent stress exponent ( $n_{\text {app }}=2$ vs. $\left.n=1\right)$, it cannot explain the very low creep constant and activation energy observed for DSC-Mg.

An alternate model without threshold stress was developed by Clegg and Martin [15] who considered grain-boundary sliding occurring by motion of grainboundary dislocations which bypass the grainboundary particles by bowing between them. If the resulting Orowan loops were to accumulate during deformation, their backstress would prevent further dislocation bypass and eventually inhibit all deformation. However, these loops can be eliminated by shrinking under their line tension during climb at the particle interface. Thus, assuming that the overall creep rate is controlled by the interfacial climb of these Orowan grain-boundary dislocation loops piled-up against the particle, the following equation can be derived for the steady-state creep rate [15]:

$\dot{\varepsilon}=\frac{\pi \rho l^{2}}{r} \frac{G b D_{\mathrm{i}}}{k T} \frac{b}{d}\left(\frac{\sigma}{G}\right)^{2}$

where $\rho$ is the grain-boundary dislocation density, $l$ the interparticle distance, $r$ the particle radius, $b$ the matrix Burgers vector, $d$ the matrix grain size, $k$ Boltzmann's constant and $G$ is the shear modulus of the matrix (given as $G(\mathrm{MPa})=19,240-8.8 T(\mathrm{~K})$ for magnesium [12]). In Eq. (2), the diffusion coefficient $D_{\mathrm{i}}$ can be interpreted as the effective diffusion coefficient at the interface, controlling the dislocation motion at the matrix/particle interface [15]. This model has the advantage of predicting the correct stress exponent for DSC-Mg and also seems particularly appropriate to DSC-Mg because it considers explicitly grain-sliding occurring at both grain- and phase-boundaries. Indeed, the very high volume fraction of dispersoids in DSC$\mathrm{Mg}$ leads to an unusually high ratio of interfacial area (between $\mathrm{Mg}$ and $\mathrm{Y}_{2} \mathrm{O}_{3}$ phases) to grain-boundary area (between $\mathrm{Mg}$ grains) as compared with ODS-metals studied to date in the diffusional creep regime. This ratio is about 0.5 for DSC-Mg, i.e. there is half as much ceramic-metal interfacial area as metal-metal grainboundary area.

Assuming that the above model can be used to describe diffusional creep of DSC-Mg, Eq. (2) can be fitted to the creep data of Fig. 1, using the measured value of $2 r=0.33 \mu \mathrm{m}$ and $d=1 \mu \mathrm{m}$, literature values for $G$ and $b$ [12], and a physically reasonable value of $\rho=1 / 1$. The fitting parameter is the effective interfacial diffusion coefficient expressed as $D_{\mathrm{i}}=D_{\text {oi }} \exp \left(-Q_{\mathrm{i}} /\right.$ $R T$ ), with pre-exponential constant $D_{\mathrm{oi}}=2 \times 10^{-16} \mathrm{~m}^{2}$ $\mathrm{s}^{-1}$ and activation energy $Q_{\mathrm{i}}=53 \mathrm{~kJ} \mathrm{~mol}^{-1}$. Ashby and Centamore [16] showed that diffusion of both matrix and dispersoid atoms is necessary for the motion of ceramic particles dragged by migrating metallic grain boundary. Similarly, in our case where particle motion is due to diffusional creep in DSC-Mg, we expect diffusion of atoms belonging to both $\mathrm{Mg}$ and $\mathrm{Y}_{2} \mathrm{O}_{3}$ to be necessary for climb of interfacial dislocations. Given the very high melting point of $\mathrm{Y}_{2} \mathrm{O}_{3}$, it is then no surprise that the fitted effective interfacial diffusion coefficient takes values four to six orders of magnitude lower than the lattice diffusion coefficient of magnesium [12] in the temperature interval of interest. The discrepancy is seven to eight orders of magnitude when comparing to the effective grain-boundary diffusion coefficient $\delta D_{\mathrm{gb}} / d$ [12] (where $\delta$ and $D_{\mathrm{gb}}$ are the grainboundary width and diffusion coefficient).

While the low activation energy for interfacial diffusion is somewhat puzzling, we note that there are several reports of activation energies much lower for interfacial diffusion than for grain-boundary diffusion. First, Hasegawa [17] found $n_{\mathrm{app}}=2$ and $Q_{\mathrm{app}}=0.5 Q_{\mathrm{gb}}$ for mechanically-alloyed aluminum containing 7 vol.\% of fine aluminum carbide and oxide dispersoids formed in situ, with and without the addition of $15 \mathrm{vol} . \%$ of 0.5 $\mu \mathrm{m} \mathrm{Al}_{2} \mathrm{O}_{3}$ particle. Second, recent densification experiments of cavitated DSC-Al [18] indicate that the activation energy associated with $\mathrm{Al} / \mathrm{Al}_{2} \mathrm{O}_{3}$ interfacial diffusion is significantly lower than for grain-boundary diffusion in pure aluminum $\left(Q=0.5-0.6 Q_{\mathrm{gb}}\right)$. Finally, Funn and Dutta [19] performed fiber creep push-out tests in the $\mathrm{Pb} / \mathrm{SiO}_{2}$ system and also found low values of interfacial activation energies $\left(Q=0.8 Q_{\mathrm{gb}}\right)$.

\subsection{Threshold stress in high-stress regime}

With increasing stress, dislocation-controlled creep becomes the dominant matrix deformation mechanism in DSC-Mg and the non-deforming yttria particles can then strengthen the matrix in two manners (i) by obstruction of individual dislocations (dispersion-strengthening) and/or (ii) by plastic flow constraint and load transfer (composite strengthening). The former effect is dominant in classical ODS materials with low volume fractions of submicron particles and is usually modeled by a threshold stress $[1,2,20]$. The latter effect dominates in classical metal matrix composites with high volume fractions of supramicron particles and is modeled by continuum mechanics considerations of load transfer or constrained matrix flow [21]. For particles smaller than $1 \mu \mathrm{m}$, Rösler et al. [22,23] have shown that composite strengthening is inoperative at typical creep temperatures, because interfacial diffusion along the matrix-reinforcement interface is rapid enough to relax completely all matrix constraints. An important assumption in these calculations is that interfacial diffusion is the most rapid diffusion path, so that the lattice diffusion contribution can be ignored. However, as 
discussed in the previous paragraph, the interfacial diffusion coefficient for DSC-Mg is expected to be much lower than the lattice diffusion coefficient of magnesium; then, matrix relaxation may not take place in DSC-Mg, and both dispersion- and compositestrengthening may occur simultaneously. We thus examine whether relaxation can occur by lattice diffusion alone, a conservative estimate since in reality matrix grain boundaries linking individual particles may provide a short-circuit path for flow of matrix atoms from one particle to another. We follow the original derivation by Rösler et al. [22] from which the following expression can be found for the critical strain rate below which all composite strengthening is lost if lattice diffusion is the only relaxation mechanism:

$\dot{\varepsilon}=\frac{4 \Omega D_{1}}{k T r^{2}} \sigma$

where $D_{1}$ is the lattice diffusion coefficient, $\Omega$ the atomic volume (taken as $b^{3}$ ) and $\sigma$ is the applied stress. This critical strain rate varies from $8 \times 10^{-4}$ to $8 \times$ $10^{-1} \mathrm{~s}^{-1}$ for our experimental range of temperature (573-723 K), stresses and particle size. These values are above the range of experimentally-measured strain rates for DSC-Mg (even with an additional factor $2 \pi$ in the denominator of Eq. (3), as suggested by Rösler et al. in a later publication [23]). Therefore, despite the expected lack of significant interfacial diffusion in DSC-Mg, lattice diffusion is rapid enough to completely relax matrix constraints and no composite strengthening is expected. In the following discussion, we thus consider

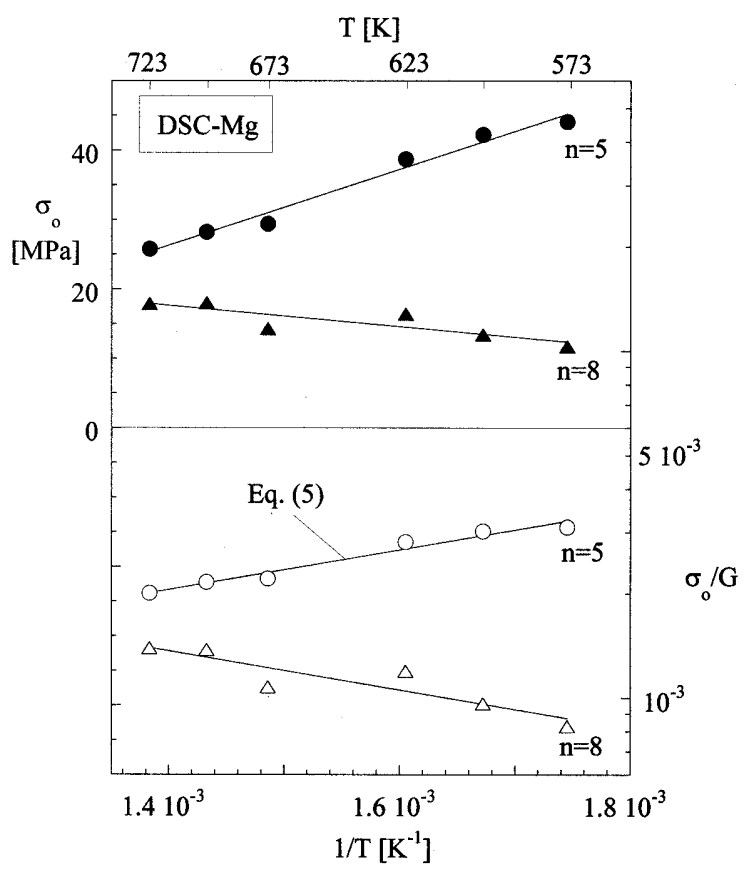

Fig. 4. Threshold stress and logarithm of the modulus-normalized threshold stress of DSC-Mg as a function of inverse temperature, as determined from the best-fit of data in Fig. 1 with Eq. (4). dispersion strengthening alone and compare our creep data to existing threshold stress models.

Thermally-activated motion of dislocations at dispersoids implies that there is no single value of the threshold stress below which dislocation motion is impossible [20]; rather, a threshold stress region exists where creep rates drop rapidly to non-measurable values. For many ODS-aluminum alloys, this critical stress region is narrow enough that it can be approximated by a single threshold stress value $\sigma_{\mathrm{o}}$, which is a convenient concept for the description of creep through a simple equation:

$\dot{\varepsilon}=\frac{A D G b}{k T}\left(\frac{\sigma-\sigma_{\mathrm{o}}}{G}\right)^{n}$

where $A$ is a dimensionless constant and $D$ is the appropriate diffusion coefficient. According to Eq. (4), the magnitude of the threshold stress can be found by plotting the experimental values of $\dot{\varepsilon}^{1 / n}$ and $\sigma$ on linear axes and extrapolating linearly to $\dot{\varepsilon}^{1 / \mathrm{n}}=0$ [24]. Such plots were constructed for DSC-Mg in the high-stress regime, using the two physically-relevant values of the stress exponent, $n=5$ for power-law dislocation creep of $\mathrm{Mg}$ [12] and $n=8$ for constant-structure dislocation creep [25]. Both stress exponents resulted in linear fits of comparable quality, from which threshold stresses were determined. Fig. 4 shows the temperature dependence of these threshold stresses, with and without normalization by the shear modulus. Since all physical models for the threshold stress predict a decrease of threshold stress with increasing temperature, we discard the values found with $n=8$ which show the opposite trend. The temperature dependence of $\sigma_{0} / G$ can then be fitted to an expression used by Mohamed et al. [26]:

$\frac{\sigma_{0}}{G}=B_{0} \exp \left(\frac{Q_{0}}{R T}\right)$

where $B_{0}$ is a constant and $Q_{0}$ is the energy associated with the binding between the dislocations and the obstacles giving rise to the threshold stress. The magnitude of the binding energy determined from Fig. 4 for $n=5$ is $Q_{0}=11 \mathrm{~kJ} \mathrm{~mol}^{-1}$.

For comparison, the threshold stress and its binding energy are listed in Table 2 for several Al-MMC and alloys produced by powder-metallurgy, where nanometer-size, incoherent oxide particles were introduced during powder atomization (or, for the case of the cast 6061-Al-MMC, where matrix precipitates transformed into incoherent platelets [33]). Also listed in Table 2 is DSC-Al, for which $Q_{0}$ was calculated based on the reported threshold stress at $n=4.4$ in [4]. Two major observations can be made by considering Table 2. First, the creep threshold stress of DSC-metals is usually higher than that of aluminum alloys or composites, as expected from the very high volume fraction of dispersoids. Second, the binding energy in aluminum alloys or 
Table 2

Creep conditions, threshold stress (Eq. (4)) and binding energy (Eq. (5)) of several AI-MMC and DSC materials

\begin{tabular}{|c|c|c|c|c|c|c|}
\hline Materials & Process $^{\mathrm{a}}$ & $T(\mathrm{~K})$ & $\dot{\varepsilon}\left(\mathrm{s}^{-1}\right)$ & $\sigma_{0}(\mathrm{MPa})$ & $Q_{0}\left(\mathrm{~kJ} \mathrm{~mol}^{-1}\right)$ & References \\
\hline $6061 \mathrm{Al}$ & $\mathrm{PM}$ & $648-678$ & $10^{-7}-10^{-1}$ & $12.6-16.4(n=5)^{\mathrm{b}}$ & 19 & [27] \\
\hline $6061 \mathrm{Al}+30 \% \mathrm{SiC}(5.1 \mu \mathrm{m})$ & PM & $618-678$ & $3 \times 10^{-9}-2.10^{-2}$ & $14.5-21.3(n=5)^{\mathrm{b}}$ & 19 & [26] \\
\hline $6061 \mathrm{Al}+20 \% \mathrm{Al}_{2} \mathrm{O}_{3}(20 \mu \mathrm{m})$ & IM & $623-773$ & $10^{-8}-10^{-3}$ & $1.8-6(n=3)^{\mathrm{b}}$ & 25 & [28] \\
\hline $2124 \mathrm{Al}$ & $\mathrm{PM}$ & $523-603$ & $10^{-9}-10^{-4}$ & $13-27(n=5)^{\mathrm{c}}$ & 23 & [29] \\
\hline $2124 \mathrm{Al}$ & PM & $618-678$ & $2 \times 10^{-9}-3.10^{-3}$ & $8.4-14.2(n=5)^{\mathrm{c}}$ & 28 & {$[30]$} \\
\hline $2124 \mathrm{Al}+10 \% \mathrm{SiC}(2.1 \mu \mathrm{m})$ & PM & $618-678$ & $2 \times 10^{-9}-6.10^{-3}$ & $18.6-30.2(n=4.5)$ & 25 & [31] \\
\hline $6092 \mathrm{Al}$ & $\mathrm{PM}$ & $623-723$ & $2 \times 10^{-9}-3.10^{-3}$ & $2.6-8.6(n=3)^{\mathrm{c}}$ & 38 & [32] \\
\hline $6092 \mathrm{Al}+25 \% \mathrm{SiC}(8 \mu \mathrm{m})$ & PM & $673-773$ & $2 \times 10^{-9}-10^{-2}$ & $2.5-7.5(n=3)^{\mathrm{c}}$ & 44 & [32] \\
\hline \multirow[t]{2}{*}{$\mathrm{Al}+25 \% \mathrm{Al}_{2} \mathrm{O}_{3}(0.28 \mu \mathrm{m})$} & IM (DSC-Al) & $673-723$ & $\begin{array}{l}10^{-9}-10^{-4}, \text { Coarse } \\
\text { grain }\end{array}$ & $50-59(n=4.4)^{\mathrm{d}}$ & 8 & [4] \\
\hline & & & $\begin{array}{l}2 \times 10^{-9}-2.10^{-3}, \text { Fine } \\
\text { grain }\end{array}$ & $65-74(n=4.4)^{\mathrm{d}}$ & 11 & [4] \\
\hline $\mathrm{Mg}+30 \% \mathrm{Y}_{2} \mathrm{O}_{3}(0.33 \mu \mathrm{m})$ & IM (DSC-Mg) & $573-723$ & $10^{-9}-10^{-3}$, Fine grain & $24-44(n=5)^{\mathrm{d}}$ & 11 & Present work \\
\hline
\end{tabular}

a PM, powder-metallurgy; IM, ingot metallurgy.

${ }^{\mathrm{b}}$ Measured on double-shear specimens (reported as $\sigma_{0}=2 \tau_{0}$ ).

${ }^{\mathrm{c}}$ Measured on tensile specimens.

${ }^{\mathrm{d}}$ Measured on compression specimens.

composites is larger than in DSC-Al or DSC-Mg with unalloyed matrix, a difference which is probably linked to the details of dislocation/particle interaction and thus the nature of the interface. Both the high threshold stress and the low temperature-dependence shown by DSC-materials are technologically desirable for a creepresistant material. We note that creep data were collected under compressive conditions only for DSC-Al and $\mathrm{DSC}-\mathrm{Mg}$, and it is known that the apparent threshold stress for DSC-Al decreases in tension due to cavitation [4].

Because DSC-Al and DSC-Mg exhibit similar matrix grain size, particle diameter, and incoherent matrixdispersoid interface, the physical origin of the threshold stress is expected to be the same in these two materials. Therefore, the threshold stress of DSC-Mg is discussed in the following in a manner similar to DSC-Al in [4,5]. The stress needed for a matrix dislocation to bypass dispersoids by bowing on its glide plane is given by the Orowan stress, $\sigma_{\text {or }}[34]$

$\sigma_{\text {or }}=M \frac{0.4 G b}{\pi \bar{\lambda}} \frac{\ln (\bar{d} / b)}{\sqrt{1-v}}$

where $M$ is the matrix mean orientation factor $(M=6.5$ for cast or extruded magnesium [35]) and $v$ is the matrix Poisson's ratio $(v=0.35[10])$. In Eq. (5), $\bar{d}=2(2 / 3)^{1 / 2} r$ is the mean diameter of a circular section in a random plane for a spherical particle of radius $r$, and $\bar{\lambda}=\bar{d}((\pi /$ $\left.4 f)^{1 / 2}-1\right)$ is the mean interparticle distance, with $f$ as the dispersoid volume fraction.

For stresses below the Orowan stress where dislocation slip is blocked by the dispersoids, dislocation motion can occur by climb of dislocations about the dispersoids. However, climb necessitates an increase of dislocation line length, resulting in a threshold stress below which climb is not energetically favorable. In the local climb model $[34,36]$, the non-climbing portion of the dislocation remains in the slip plane while the climbing portion assumes the shape of the spherical particle. In the general climb model [37] where the climbing portion of the dislocation line exceeds the particle size, the total dislocation line length is then decreased by a factor $\kappa$ and the threshold stress is given by:

$\sigma_{\text {gen }}=0.4 \kappa \sigma_{\text {or }}$.

The climb factor $\kappa$ is only a function of the particle volume fraction [38] and takes a value $\kappa=0.62$ for DSC-Mg. In the local climb model where only the dislocation line in contact with the dispersoids can climb, $\kappa$ is unity. The cooperative climb mechanism [38] considers dislocation climb over groups of particles instead of individual particles; it is not discussed here because it predicts no increase in apparent stress exponent and activation energy, in contradiction with our experimental data.

A different threshold mechanism is considered in the detachment model [39], where after climbing over a particle, the dislocation must overcome an attractive force due to elastic relaxation at the incoherent particle/ matrix interface. This detachment threshold stress $\sigma_{\text {det }}$ is given by [40]:

$\sigma_{\text {det }}=\zeta \sqrt{1-k_{\mathrm{r}}^{2}} \sigma_{\text {or }}$

where the correction factor $\zeta=\bar{\lambda} / L[5]$ must be used for high volume fractions of dispersoids (with $L=r(4 \pi /$ $3 f)^{1 / 3}$ as the center-to-center dispersoid spacing). For ODS-materials with low volume fractions of disper- 
soids, the relaxation factor $k_{\mathrm{r}}$ in Eq. (8) can be calculated from $n_{\text {app }}, Q_{\text {app}}, G$ and $r$ as described in [41]. While the low volume fraction condition is not fulfilled in DSC-Mg, it is instructive to calculate values of the relaxation factor from our experimental results at 60 MPa: $k_{\mathrm{r}}$, varies from 0.9895 to 0.9885 as temperature increases from 573 to $723 \mathrm{~K}$. Values of relaxation factor so close to unity indicate a very weak interaction between particles and dislocations.

Fig. 5 shows the local, general and detachment threshold stresses calculated from Eqs. (7) and (8), as well as the threshold stress determined experimentally using $n=5$ (Fig. 4). Since local and general climb are concurrent mechanisms, the climb mechanism with the lowest threshold is controlling (i.e., general climb). However, since general climb and detachment are sequential mechanisms, the highest threshold value should correspond to the overall threshold stress measured experimentally. Thus, according to Fig. 5, the general threshold stress $\left(\sigma_{\text {gen }} \approx 45 \mathrm{MPa}\right)$ should be determinant. While this prediction matches the experimental value $\left(\sigma_{\mathrm{o}} \approx 42 \mathrm{MPa}\right)$ quite well from 573 to 623 $\mathrm{K}$, it overpredicts the measured threshold stress between 673 and $723 \mathrm{~K}\left(\sigma_{\mathrm{o}} \approx 28 \mathrm{MPa}\right)$. As discussed in the following, neither the good match at lower temperature nor the discrepancy at higher temperature can however be accepted uncritically.

For dispersion-strengthened materials with relatively coarse dispersoids such as DSC-Al or DSC-Mg, experimental observations and theoretical calculations show that there are more than one dislocation for each particle, and that these lattice dislocations form pile-ups against dispersoids [5]. Thus, the rate-controlling dislocations climbing above, or detaching from, the disper-

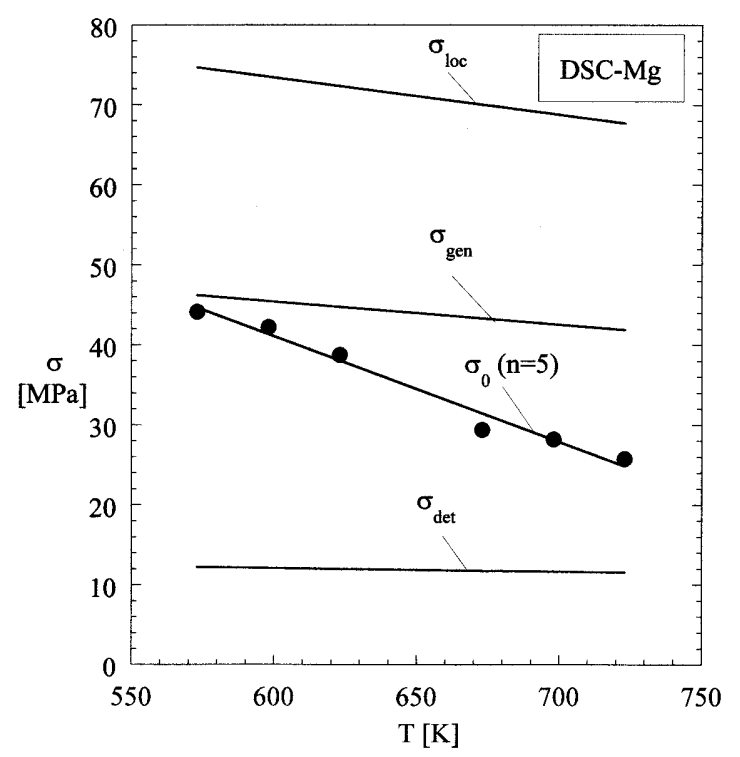

Fig. 5. Comparison of theoretical predictions and experimental results for the threshold stress of DSC-Mg. soids are subjected to a back-stress from each of the other dislocations piled-up at the dispersoids. The resulting pile-up stress $\sigma_{\mathrm{p}}$, which is the sum of the elastic stresses from all neighboring dislocations at the location of the rate controlling (climbing or detaching) dislocation, can be positive or negative depending on particle and pile-up geometry. The overall threshold stress $\sigma_{\text {th }}$ is then the sum of this pileup stress $\sigma_{\mathrm{p}}$ and the relevant threshold stress for low volume fractions of dispersoids (Eq. (7) or Eq. (8)). This model [5] was applied to DSC-Al where the rate-controlling mechanism was known to be detachment and the relaxation factor had been independently measured on low volume fraction $\mathrm{Al} / \mathrm{Al}_{2} \mathrm{O}_{3}$ materials $\left(k_{\mathrm{r}}=0.80\right.$ [42]). For DSC$\mathrm{Al}$, the pile-up stress was found to be positive, i.e. the overall threshold stress was larger than the detachment stress calculated from Eq. (8) for low volume fractions of dispersoids under the assumption that no pile-ups exist [5].

For the particle size and volume fraction in DSC$\mathrm{Mg}$, the number of dislocations per particles is estimated as 5-10 [5], so it is very likely that pile-ups of dislocation form during creep of DSC-Mg, as experimentally observed in DSC-Al [4]. To justify the experimental threshold stress values in Fig. 5, the pile-up stress must decrease the high value of the general climb threshold stress at high temperatures. Alternatively, the pile-up stress could increase a low value of the detachment stress (calculated here with $k_{\mathrm{r}}=0.99$ ) at all temperatures, while also depressing the climb threshold stress. However, a computation of the pile-up stress for DSC-Mg is not carried out here, because it would not allow to discriminate between the two threshold mechanisms. This is because the true detachment stress in the $\mathrm{Mg} / \mathrm{Y}_{2} \mathrm{O}_{3}$ system is unknown. Indeed, the above value calculated with $k_{\mathrm{r}}=0.99$ and shown in Fig. 5 relies on a determination of $k_{\mathrm{r}}$ from $n_{\text {app }}$ and $Q_{\text {app }}$ which is only valid if the pile-up stress is zero. For DSC-Mg where a pile-up stress exists, the parameter $k_{\mathrm{r}}$ must be determined independently on $\mathrm{Mg} / \mathrm{Y}_{2} \mathrm{O}_{3}$ materials with low volume fractions of dispersoids $(f<0.1)$ where the condition $\sigma_{\mathrm{p}}=0$ is fulfilled. The resulting detachment stress may then well be much higher than the values shown in Fig. 5, and may even exceed the general climb value. However, to the best of our knowledge, such low-volume-fraction materials are not commercially available and have never been studied.

In summary, DSC-Mg shows a threshold stress which is $60-97 \%$ of the calculated value of the general climb threshold stress. Because of the very high volume fractions of dispersoids, DSC-Mg is expected to exhibit dislocation pile-ups, the back-stress of which may be sufficient to decrease the calculated general climb threshold stress to the observed values. Alternatively, detachment control may be dominant, but altered by the pile-up back-stress. However, the detachment 

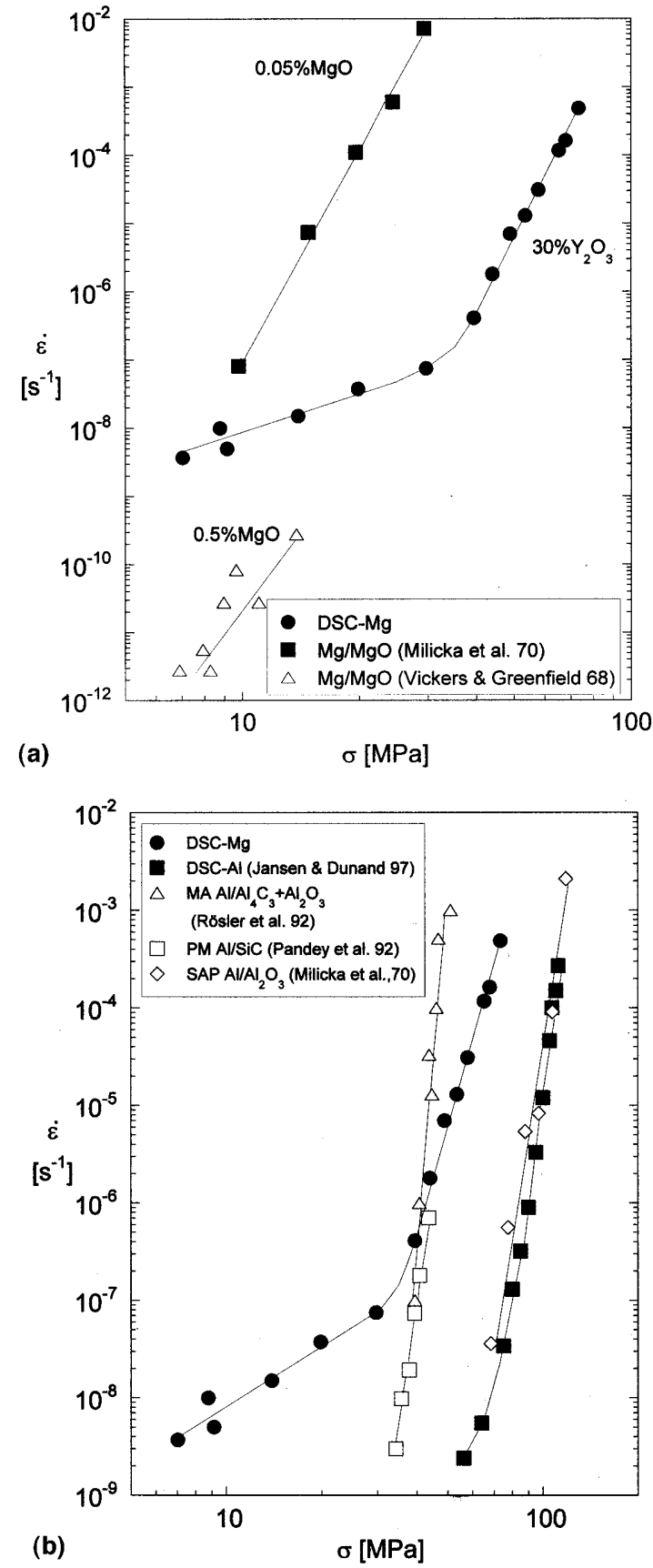

Fig. 6. Comparison of creep behavior at $673 \mathrm{~K}$ between DSC-Mg and (a) ODS magnesium; (b) creep-resistant aluminum materials (DSC$\mathrm{Al}$, ODS-Al and $\mathrm{Al}-\mathrm{MMC}$ ).

threshold stress cannot be calculated without determining the relaxation factor from an independent experiment on a low-volume-fraction material.

\subsection{Comparison of creep resistance of DSC-Mg with other materials}

It is difficult to compare DSC-Mg with heat-treatable magnesium alloys, because the upper creep-temperature dictated by rapid coarsening and/or dissolution of pre- cipitates in these alloys [43] is below the lowest test temperature of DSC-Mg. A few creep data exist in the temperature range $573-623 \mathrm{~K}$ for some of the most stable high-temperature Mg-alloys. For example, strainrates of $2-4 \times 10^{-8} \mathrm{~s}^{-1}$ are reported for $\mathrm{Mg}-6 \mathrm{Y}-$ $4 \mathrm{Zn}-2 \mathrm{Nd}-0.7 \mathrm{Zr}$ and $\mathrm{Mg}-6 \mathrm{Y}-3 \mathrm{Nd}-0.7 \mathrm{Zr}$ at $573 \mathrm{~K}$ and $20 \mathrm{MPa}$ [43], which are comparable to the value of $4 \times 10^{-8} \mathrm{~s}^{-1}$ measured for DSC-Mg (Fig. 1). We note that the above alloys can be expected to be much less corrosion- and oxidation-resistant than DSC-Mg because of the large additions of transition metals. Given the inert electro-chemical and chemical nature of $\mathrm{Y}_{2} \mathrm{O}_{3}$, DSC-Mg should however exhibit the same good oxidation and corrosion behavior as pure, unalloyed magnesium [10]. Our creep experiments indeed show that oxidation of DSC-Mg is slow in air up to $723 \mathrm{~K}$.

At temperatures above $623 \mathrm{~K}$, the only existing Mgbased materials with potentially good long-term creep resistance are Mg-MMCs and ODS-Mg. Two creep studies exist for ODS-Mg produced by controlled oxidation of magnesium powders followed by powdermetallurgy densification: $\mathrm{Mg}$ with 0.05 vol. $\% \mathrm{MgO}$ particles [8] and 0.5 vol. $\% \mathrm{MgO}$ particles [44]. Fig. 6a shows that, similarly to DSC-Mg, both fine grained materials exhibit high stress exponent and strongly-inhibited diffusional creep. DSC- $\mathrm{Mg}$ and $\mathrm{Mg}-0.5 \% \mathrm{MgO}$ have comparable dislocation creep performance, despite the large difference in oxide volume fraction. This is because the flake-like magnesia particles in $\mathrm{Mg}-$ $0.5 \% \mathrm{MgO}$ have approximate dimensions $0.1 \times 0.3 \times 0.3$ $\mu \mathrm{m}$ [44] and are thus significantly smaller than the 0.33 $\mu \mathrm{m}$ equiaxed yttria particles in DSC-Mg. This partially compensates for the lower volume fraction in the Orowan stress equation (Eq. (6)). Another possible important difference is the nature of the metal/oxide interface, which may be more effective at trapping detaching dislocations for $\mathrm{MgO}$ than for $\mathrm{Y}_{2} \mathrm{O}_{3}$. A similar effect was found by Rösler et al. [42] in dispersionstrengthened aluminum alloys, where the $\mathrm{Al} / \mathrm{Al}_{4} \mathrm{C}_{3}$ interface has a stronger interaction with dislocation than the $\mathrm{Al} / \mathrm{Al}_{2} \mathrm{O}_{3}$ or $\mathrm{Al} / \mathrm{MgO}$ interfaces, leading to a more effective pinning of dislocations and higher creep resistance.

Finally, it is instructive to compare DSC-Mg to creep-resistant aluminum-based materials with similar density: (i) extruded DSC-Al with 25 vol. $\% \mathrm{Al}_{2} \mathrm{O}_{3}$ dispersoids $0.28 \mu \mathrm{m}$ in diameter [4], (ii) mechanically-alloyed aluminum (MA-Al) with 0.11 vol. $\% \mathrm{Al}_{4} \mathrm{C}_{3}$ and 1.75 vol. $\% \mathrm{Al}_{2} \mathrm{O}_{3}$ about $30 \mathrm{~nm}$ in size [42], (iii) extruded, sintered aluminum powders (SAP) with about 10 vol. $\% \mathrm{Al}_{2} \mathrm{O}_{3}$ finer than $0.15 \mu \mathrm{m}$ [45] and (iv) AlMMC containing $20 \mathrm{vol} \% \mathrm{SiC}$ particles $1.7 \mu \mathrm{m}$ in diameter (and about 0.16 vol. $\%$ of very fine $8.8 \mathrm{~nm}$ $\mathrm{Al}_{2} \mathrm{O}_{3}$ particles introduced during atomization before powder compaction) [46]. As shown in Fig. 6b, the dislocation creep resistance at $673 \mathrm{~K}$ of DSC-Mg is 
similar to that of MA-Al and Al-MMCs which contain low volume fractions of very fine dispersoids, but significantly inferior to that of DSC-Al and SAP materials, despite their lower volume fractions as compared with DSC-Mg. As for the $\mathrm{Mg} / \mathrm{MgO}$ materials discussed above, differences in dispersoid size, fraction and interface are all expected to play a role in the relative creep resistance of these materials.

A comparison is most meaningful with DSC-Al, which exhibits dispersoid size and volume fraction similar to DSC-Mg. At $673 \mathrm{~K}$, the threshold stress of DSC-Al is almost twice that for DSC-Mg (Table 2). This large discrepancy cannot be explained by the matrix creep behavior, as pure magnesium creeps somewhat more slowly than pure aluminum for the stress and temperature range studied here [12]. Similarly, the climb threshold stress (Eq. (7)) is nearly identical for both materials, because the Orowan stress (Eq. (6)) takes almost the same value in both DSC-materials (the larger dispersoid size of DSC-Mg is compensated by its larger volume fraction). Two possible factors can then be put forward to explain the large difference in threshold stresses between both DSC materials.

First, the detachment threshold stress could be lower (i.e. the relaxation factor higher) for the $\mathrm{Mg} / \mathrm{Y}_{2} \mathrm{O}_{3}$ system than for the $\mathrm{Al} / \mathrm{Al}_{2} \mathrm{O}_{3}$ system. An improvement in creep properties of DSC-Mg could then be achieved by replacing $\mathrm{Y}_{2} \mathrm{O}_{3}$ with another material displaying a lower relaxation factor with respect to magnesium. Due to the DSC fabrication technique, the choices are however limited to ceramics which are thermodynamically stable with liquid magnesium (e.g. $\mathrm{MgO}, \mathrm{BeO}, \mathrm{ThO}_{2}$, $\mathrm{Ce}_{2} \mathrm{O}_{3}$ or $\mathrm{Sc}_{2} \mathrm{O}_{3}$ [47]) and which do not form stable $\mathrm{Mg}$-containing ternary oxides.

Second, the pile-up stress may be different for DSC$\mathrm{Al}$ and DSC-Mg. While the interparticle distance $\bar{\lambda}$ is almost the same in both materials, the size of the dispersoids in DSC-Mg is larger, thus influencing the positions of the dislocations in pile-ups and the resulting pile-up stress acting upon the controlling detaching or climbing dislocations. Markedly improved creep resistance for DSC-Mg could then result from modest changes in particle diameter and/or volume fraction. Finally, it is possible that both above factors are responsible for the relatively low threshold stress of DSCMg.

\section{Conclusions}

DSC-Mg, consisting of unalloyed magnesium with 1 $\mu \mathrm{m}$ grain size containing $30 \mathrm{vol} . \%$ of $0.33 \mu \mathrm{m}$ yttria dispersoids, was creep-tested between 573 and $723 \mathrm{~K}$ for compressive stresses ranging from 7 to $125 \mathrm{MPa}$.

In the low-stress regime $(\sigma<30 \mathrm{MPa})$, the apparent stress exponent is about 2 at all temperatures and the apparent activation energy is $48 \mathrm{~kJ} \mathrm{~mol}^{-1}$, about half the activation energy of grain boundary diffusion in pure magnesium. The low-stress behavior can be described by an existing model of grain-boundary sliding inhibited by grain-boundaries dispersoids.

In the high-stress regime $(\sigma>34 \mathrm{MPa})$, the apparent stress exponent increases with increasing temperatures from 9 to 15 between 573 and $723 \mathrm{~K}$. The apparent activation energy increases with increasing stress from $229 \mathrm{~kJ} \mathrm{~mol}^{-1}$ at $40 \mathrm{MPa}$ to $325 \mathrm{~kJ} \mathrm{~mol}^{-1}$ at $80 \mathrm{MPa}$. The experimental threshold stress is close to the value predicted by the general climb model at low temperature but drops to about $60 \%$ of that value at the highest temperature. Similar to DSC-Al with high volume fractions of dispersoids, an additional contribution to the threshold stress is expected from dislocation pile-ups in DSC-Mg, thus possibly explaining the lower values of threshold stress at high temperature. The possibility of a threshold stress controlled by detachment in conjunction with the pile-up effect cannot however be ruled out.

DSC-Mg is very creep-resistant as compared with the best high-temperature magnesium alloys or ODS-Mg. It is however weaker than previously-studied DSC-Al (pure $\mathrm{Al}$ with $25 \mathrm{vol} . \%$ of $0.28 \mu \mathrm{m}$ alumina dispersoids), which is attributed to a lower detachment stress (due to the different nature of the metal-oxide interface) and/ or a lower pile-up stress (due to different particle size and/or fraction).

\section{Acknowledgements}

This work was supported by the National Science Foundation, under Grant No. DMR 9417636, with Dr B. McDonald as monitor.

\section{References}

[1] E. Arzt, Res. Mech. 31 (1991) 399-453.

[2] S.V. Raj, in: S. Ochiai (Ed.), Mechanical Properties of Metallic Composites, Dekker, New York, 1994, pp. 97-183.

[3] A.M. Redsten, E.M. Klier, A.M. Brown, D.C. Dunand, Mater. Sci. Eng. A201 (1995) 88-102.

[4] A.M. Jansen, D.C. Dunand, Acta Mater. 45 (1997) 4583-4592.

[5] D.C. Dunand, A.M. Jansen, Acta Mater. 45 (1997) 4569-4581.

[6] P. Greenfield, W. Vickers, J. Nucl. Mater. 22 (1967) 77-87.

[7] W. Vickers, P. Greenfield, J. Nucl. Mater. 24 (1967) 249-260.

[8] K. Milicka, J. Cadek, P. Rys, Acta Metall. 18 (1970) 1071-1082.

[9] B.Q. Han, D.C. Dunand, Mater. Sci. Eng. A277 (2000) 297-304.

[10] E.F. Emley, Principles of Magnesium Technology, Pergamon Press, Oxford, 1966.

[11] D.C. Dunand, B.Q. Han, A.M. Jansen, Metall. Mater. Trans. A 30A (1999) 829-838.

[12] H.J. Frost, M.F. Ashby, Deformation-Mechanism Maps: The Plasticity and Creep of Metals and Ceramics, Pergamon Press, Oxford, 1982, pp. 43-52.

[13] A. Ball, M.M. Hutchison, Met. Sci. J. 3 (1969) 1-7. 
[14] B. Burton, Diffusional Creep of Polycrystalline Materials, Trans Tech Publications, Switzerland, 1977.

[15] W.J. Clegg, J.W. Martin, Met. Sci. 16 (1982) 65-72.

[16] M.F. Ashby, R.M.A. Centamore, Acta Metall. 16 (1968) 10811092.

[17] T. Hasegawa, K. Minami, T. Miura, in: B. Wilshire, R.W. Evans (Eds.), Creep and Fracture of Engineering Materials and Structures, The Institute of Metals, London, 1990, pp. 159-168.

[18] C. Schuh, B.Q. Han, D.C. Dunand, Metall. Mater. Trans. A, (2000), in press.

[19] J.V. Funn, I. Dutta, Acta Mater. 47 (1999) 149-164.

[20] E. Arzt, in: S. Ochiai (Ed.), Mechanical Properties of Metallic Composites, Dekker, New York, 1994, pp. 205-223.

[21] T.W. Clyne, P.J. Withers, An Introduction to Metal Matrix Composites, Cambridge University Press, Cambridge, 1993.

[22] J. Rösler, G. Bao, A.G. Evans, Acta Metall. Mater. 39 (1991) $2733-2738$.

[23] J. Rösler, A.G. Evans, Mater. Sci. Eng. A153 (1992) 438-443.

[24] R. Lagneborg, B. Bergman, Met. Sci. 10 (1976) 22-28.

[25] J. Lin, O.D. Sherby, Res. Mech. 2 (1981) 251-293.

[26] F.A. Mohamed, K.-T. Park, E.J. Lavernia, Mater. Sci. Eng. A150 (1992) 21-35.

[27] K.-T. Park, E.J. Lavernia, F.A. Mohamed, Acta Metall. Mater. 42 (1994) 667-678.

[28] Y. Li, T.G. Langdon, Acta Mater. 45 (1997) 4797-4806.

[29] L. Kloc, S. Spigarelli, E. Cerri, E. Evangelista, T.G. Langdon, Acta Mater. 45 (1997) 529-540.
[30] Y. Li, S.R. Nutt, F.A. Mohamed, Acta Mater. 45 (1997) 26072620.

[31] Y. Li, F.A. Mohamed, Acta Mater. 45 (1997) 4775-4785.

[32] Y. Li, T.G. Langdon, Metall. Mater. Trans. A 29A (1998) $2523-2531$.

[33] Y. Li, T.G. Langdon, Mater. Sci. Eng. A245 (1998) 1-9.

[34] L.M. Brown, R.K. Ham, in: A. Kelly, R.B. Nicholson (Eds.), Strengthening Methods in Crystals, Elsevier, Amsterdam, 1971, pp. $9-135$.

[35] R. Armstrong, L. Codd, R.M. Douthwaite, N.J. Petch, Phil. Mag. 7 (1962) 45-57.

[36] R.S.W. Shewfelt, L.M. Brown, Phil. Mag. 35 (1977) 945-962.

[37] R. Lagneborg, Scr. Metall. 7 (1973) 605-614.

[38] M. McLean, Acta Metall. 33 (1985) 545-556.

[39] D.J. Srolovitz, M.J. Luton, R. Petkovic-Luton, D.M. Barnett, W.D. Nix, Acta Metall. 32 (1984) 1079-1088.

[40] E. Arzt, D.S. Wilkinson, Acta Metall. 43 (1986) 1893-1898.

[41] J. Rösler, E. Artz, Acta Metall. Mater. 38 (1990) 671-683.

[42] J. Rösler, R. Joos, E. Arzt, Metall. Trans. 23A (1992) 15211539.

[43] B.L. Mordike, W. Henning, Magnesium Technology, The Institute of Metals, London, 1986, pp. 54-59.

[44] W. Vickers, P. Greenfield, J. Nucl. Mater. 27 (1968) 73-79.

[45] K. Milicka, J. Cadek, P. Rys, Acta Metall. 18 (1970) 733-746.

[46] A.B. Pandey, R.S. Mishra, Y.R. Mahajan, Acta Metall. Mater. 40 (1992) 2045-2052.

[47] T.B. Reed, Free Energy of Formation of Binary Compounds, MIT Press, Cambridge, 1971. 